\title{
Investigation and Countermeasure Research on the Learning Adaptability of the First-Year Junior High Freshman
}

\author{
Xiulin Ma, Chenyu Fan*, Zhinie Nie, Yujuan Jia \\ Faculty of Education, Beijing Normal University, Beijing, China \\ Email: maxl@bnu.edu.cn, *ssfanlmz@163.com,201911010113@mail.bnu.edu.cn, Jyujuan8807@163.com
}

How to cite this paper: Ma, X. L., Fan, C. Y., Nie, Z. N., \& Jia, Y. J. (2021). Investigation and Countermeasure Research on the Learning Adaptability of the First-Year Junior High Freshman. Open Journal of Social Sciences, 9, 70-90.

https://doi.org/10.4236/jss.2021.98007

Received: July 16, 2021

Accepted: August 3, 2021

Published: August 6, 2021

Copyright (อ 2021 by author(s) and Scientific Research Publishing Inc. This work is licensed under the Creative Commons Attribution International License (CC BY 4.0).

http://creativecommons.org/licenses/by/4.0/ (c) (i) Open Access

\begin{abstract}
Learning adaptability refers to the ability tendency of students to adjust themselves to overcome various difficulties and achieve better learning results in the learning process, which has a direct impact on students' learning enthusiasm and academic performance. In order to objectively reflect the characteristics and current situation of the learning adaptability development of the first-year junior high freshmen under the "new curriculum reform", the study used student questionnaire and teacher questionnaire to conduct two rounds of one-year investigation on the learning adaptability of 329 freshmen from the aspects of learning attitude and habit, learning ability, learning method, etc. In addition, to ensure the objectivity of the results, the relevant conclusions were verified by using the class rank and grade rank of students' monthly examination results. Two rounds of surveys shown that there is a significant correlation between the gender of students, the family background of students and the self-assessment results of learning adaptability of the freshmen of the first-year junior high school. In addition, the self-assessment results of students' learning adaptability are strongly influenced by their subjectivity and class rank. In school education, schools and teachers should pay more attention to the "middling" group of students, and strengthen the attention to the psychological health of students who are lower in the quality class, especially to the cultivation of their self-confidence and self-management ability.
\end{abstract}

\section{Keywords}

Learning Adaptability, First-Year Junior High Freshman, "Middling" Students 


\section{Introduction}

In the process of promoting quality-oriented education in an all-round way, the research on the learning adaptability has attracted the attention of many scholars. From the perspective of psychology, learning adaptability refers to the ability of individuals to actively overcome difficulties and change themselves in order to avoid or change the decline of learning effectiveness when the learning environment, learning objects and contents around them change. In China, the status quo of students' learning adaptability shows significant differences between different genders and different grades (Nie, Zheng, \& Zhang, 2004). Learning adaptability has a direct impact on academic performance (Liu, Liu, \& You, 2015). Learning adaptability can directly affect the learning effect of students. Good learning adaptability can promote the improvement of students' psychological quality and the construction of interpersonal relationship, and ensure the quality of students' learning (Zhao, Huang, Yang, \& Zhao, 2018).

The first year of junior high school is the critical period for students to adapt to the life there. For freshmen who leave primary school to enter junior high school, many changes take place in the learning situation. First of all, the categories of courses increase, the amount of learning multiplies, and the content of the subject tends to be specialized and abstract. As a result, students' learning activities become more and more abundant, including not only knowledge learning, understanding learning, applied learning, but also analysis learning, comprehensive learning and review learning. The change of learning content is bound to require junior high school students to learn to form new learning ability and adapt to new learning activities (Li \& Zhang, 2004). These changes may bring many freshmen learning adaptation problems, learning interest decline, bad behavior habits, emotional instability, and even lower academic performance, seriously affecting the normal development of their academic career and the healthy growth of body and mind. The investigation and research on the learning adaptation level of primary and middle school students in China mainly focus on the last century and this century. However, the existing studies have not deeply explored the differences in the dimensions of students' learning adaptation, and the analysis of the aspects of students' learning adaptation is not clear (Liu, Fang, \& Jin, 2019). Therefore, the original intention of the study is to understand the rules of adaptation in learning of first-year freshmen of the junior high, so as to make schools and families more scientific and comprehensive understanding and analysis of students' learning, and further take targeted guidance measures and solutions to help students to learn and lay a good foundation for future learning.

Through the questionnaire surveys of freshmen themselves, teachers' assessment of their learning adaptability, parents' educational background and subsequent data analysis, analyze the current situation of learning adaptability of junior high school freshmen under the new curriculum reform from the perspective of learning methods and learning ability, learning attitude and learning ha- 
bits. According to the survey data, classify, track and analyze the changes of the first-year freshmen of junior high school. Explore the factors that affect the learning adaptability level of junior high school students, and put forward targeted adjustment countermeasures for students.

\section{Literature Review}

\subsection{The Definition of Learning Adaptability by Scholars in China}

Chinese researches quote: "Learning adaptability, is an ability tendency to overcome various difficulties and achieve better learning results (Li \& Shi, 1998)". The definition focuses more on the results, takes the learning effect as a measure of learning adaptability, and deviates from the concept of "adaptation". Xu Zhening and Zheng Miaochen believed that learning adaptability refers to students' aptitude to adjust themselves and adapt to learning environment in the process of learning. Tian Lan put forward that learning adaptability was the ability that students adjust their body and mind actively according to the changes of learning conditions in the process of learning, so as to achieve the favorable development state of the balance of internal and external learning environment (Tian, 2004). Feng Tingyong and other scholars believed that learning adaptability was a psychological and behavioral process in which the subject tries to adjust himself according to the environment and the needs of learning, so as to achieve a balance with the learning environment (Feng, $\mathrm{Su}, \mathrm{Hu}, \& \mathrm{Li}, 2006$ ). In the above definitions, scholars defined learning adaptability as an ability or a gradual process. The author believed that "learning adaptability" refers to the ability tendency of students to adjust themselves to the learning environment and learning process in the process of learning, and this ability tendency was the synthesis of a variety of psychological factors (Han, 2006).

\subsection{Influence Factors Analysis of Students' Learning Adaptability}

The influence factors of learning adaptability are divided into students' own internal factors and external environmental factors. The internal factors of students themselves mainly include cognitive style, personality characteristics and mental health, individual differences and learning motivation. The external environmental factors mainly include family and school factors.

\subsubsection{Internal Influence Factors Influencing Students' Learning Adaptability}

In terms of students' personality factors, Judy's research shown that college students' self-assessment, sense of responsibility and expectation of becoming excellent will have a great influence on their learning adaptability in the first academic year, and further affect their subsequent learning adaptability and academic achievement (Chartrand, 1990). When teachers' and students' cognitive style were fully matched, students' learning adaptation is the best (adaptation refers to academic performance, learning attitude, teacher-student relationship, etc.). The teacher-student with inappropriate cognitive styles and types have 
poor learning adaptation. Martin et al. found that optimism, academic self-efficacy and coping ability were significantly positively related to college students' academic expectation and learning adaptability (Chemers, Hu, \& Carcia, 2001). Song Guangwen believed that students with strong learning adaptability had some obvious personality characteristics, which were manifested as stable and mature emotions, and the calm attitude towards reality and various problems. Students with high learning adaptability had a good level of mental health (Song, 1999).

The individual differences of the research on learning adaptability mainly include age and gender differences. Age was an important factor which affects learning adaptability. Research by Zhang Lihua and Zhang Li shown that students' learning adaptability has a downward trend with the increase of grade: the students in grade 7 were significantly lower than those in grade 6 , and students in grade 8 were even lower than those in grade 7 . In the dimensions of learning attitude and learning method, the same situation also appears (Zhang, \& Zhang, 2006). Zhang Chengfen and Zhang Jinbao found that although learning adaptability increase with grade, the difference was not significant (Zhang \& Zhang, 2000). Learning adaptability didn't naturally improve with the increase of students' age. It is mainly the learned result, and relatively stable once a certain tendency is formed.

Gender was also an important factor affecting learning adaptability. In the research of Li Huili and Zhang Qinglin, it was pointed out that girls are significantly better than boys in the total score of learning adaptability, learning habits and enthusiasm, autonomy and motivation, and teaching methods. Tian Lan and Zhang Dajun reported that the overall level of learning adaptability of girls was significantly higher than that of boys, but with the increase of grade, the gender difference gradually narrow (Tian \& Zhang, 2004). Dai Yuhong found that the AAT total score of male students in urban junior high school was slightly lower than that of female students, but the difference was not significant (Dai, 1997). On the contrary, Zeng Jing's report shown that there were significant differences in the overall level of learning adaptability and learning attitude between girls and boys, and the average score of girls was significantly higher than that of boys (Zeng, 2007).

\subsubsection{External Influence Factors Affecting Students' Learning Adaptability}

All kinds of factors in the family (such as family structure, etc.) and the characteristics of parents (such as parents' education level, etc.) will directly or indirectly affect children's physical and mental development, and will inevitably affect the development of learning adaptability (Wei, 2004).

In the existing researches in China, the differences of school location (the source of students) and school type have been analyzed as the factors influencing students' learning adaptability. Ge Minggui and Yu Yibing studied college students' learning adaptability and its influencing factors, and found that teaching 
methods, learning attitude, curriculum and learning methods were the main reasons for poor learning adaptability ( $\mathrm{Ge} \& \mathrm{Yu}, 2005)$. Liao Xuerong found that there were differences in English learning adaptability among students in different types of high schools, and the English learning adaptability of students in key high schools was significantly better than that of students in non-key high schools (Liao, 2014). Bian Yanling and Tan Ming found that the learning adaptability of children of floating population was generally above the average level, and the learning adaptability was significantly lower than that of local students (Bian \& Tan, 2017). Li Huili and Zhang Qinglin also pointed out that the factors of learning adaptability have significant differences in the source areas of students and school types. The students from urban areas were significantly better than those from rural areas, and the students from key schools were significantly better than those from non-key schools. The survey of Bai Jinrong and others shown that the detection rates of poor learning adaptability of male and female students in rural middle schools account for $45.56 \%$ and $21.43 \%$ respectively (Bai, Liu, \& Guo, 1997).

The teacher-student relationship and peer relationship established also affected the development of learning adaptability. Teachers were the key factors that affected learning adaptability. In the interaction between teachers and students, teachers' assessment of students' behavior, emotional reaction and behavior performance affect students' experience and assessment of themselves, especially the psychological factors in students' personality development, such as self-awareness and self-esteem (Santalucia, Gesten, Rendina-Gobioff, Esptein, Kaufmann, Salcedo et al., 2000). Peer were another important factor affecting the development of learning adaptability. Especially when children were promoted from primary school to junior high school, peer can provide more opportunities for children to develop skills compared with parents and teachers. Only when they were compared with their peers can they form their own cognition and assessment. Only when children were accepted and welcomed by their peers in interactions can they form a positive assessment of themselves and improve their learning adaptability.

\section{Research Scheme Design Methodology}

\subsection{Questionnaire Survey}

The study mainly used the questionnaire survey method to investigate level of students' learning adaptability from the perspectives of students themselves and teachers.

\subsubsection{Design of Investigation Index}

1) Student-oriented questionnaire

The study used the Middle School Students' Learning Adaptability Measurement compiled by Lai lugui. The questionnaire eliminated 3 questions that did not involve the curriculum content of first grade of junior high school, with a total of 96 questions, including 42 questions about learning methods, 28 ques- 
tions about learning ability, and 26 questions about learning attitude and learning habits. The whole test was required to be completed within half an hour.

2) The index of the third-party assessment led by the head teacher

The assessment of students' learning adaptability led by the head teacher usually came from the head teacher' intuitive feelings of each student. In order to ensure the rigor of the research, this study set up the Students' Learning Adaptability Assessment Index (version used by teachers) to make objective assessments from the aspects of learning attitude and habits, learning ability, learning methods, learning enthusiasm, academic achievement, classroom performance, homework completion, etc.

\subsubsection{Research Objects}

In order to understand the law and characteristics of learning adaptability of freshmen in the first grade of junior high school under the new curriculum reform, this study investigated 329 freshmen in A school, in order to comprehensively grasp their level of learning adaptability.

There were 159 female and 170 male students. Among them, 50 students from other provinces, 29 male and 21 female students. It could be seen that the distribution proportion of respondents was relatively balanced in terms of gender and source of students, and the sample has good representativeness.

\subsubsection{Reliability and Validity of Assessment Tools}

The Middle School Students' Learning Adaptability Measurement was compiled by Lai lugui, which had been verified by many people and had good reliability and validity. Students' Learning Adaptability Assessment Index (version used by teachers) was compiled by the author. The author invited three experts from Beijing Normal University to review the assessment index, which ensured its structural validity.

Organized the students to fill in the questionnaire during the class meeting. This strategy avoided the leakage of questionnaire content and students' psychological preparation in advance, which may interfere with the validity of the questionnaire. The head teacher in each class provided guidance before students filled in the questionnaire and monitored the students to finish the questionnaire. The whole test was generally required to be completed within half an hour. Those not completed within the required time didn't participate in the statistical analysis as valid test papers.

In addition, in order to test the reliability and validity of the questionnaire, the time difference between the pre-test questionnaire and the monthly test was less than one week. The correlation analysis between the monthly test results and the validity data of the questionnaire was carried out to verify the validity of the survey data of learning adaptability.

\subsection{Research Process}

This study mainly started from the survey data, requiring students to use the Middle School Students' Learning Adaptability Measurement questionnaire for 
self-assessment, and requiring teachers to use the Students' Learning Adaptability Assessment Index (version used by teachers) to make a third-party objective assessment of the students in their class. The specific process of this study is shown in Figure 1.

In order to pay attention to the changes of students' adaptability in the first year of junior high school and ensure the objectivity of the research, this study decided to conduct two rounds of questionnaire surveys on students and teachers, namely, the pre-test of students' self-assessment of learning adaptability and the pre-test of teachers' third-party objective assessment of the students in their class led by head teachers at the beginning of the first year of junior high school, the post-test of students' self-assessment of learning adaptability and the posttest of teachers' third-party assessment at the end of the first year, with a oneyear interval between them. In order to assess students' learning adaptability more objectively, this study used students' test scores and teachers' assessment to verify and revise students' self-assessment results.

This study adopted 5-point scoring method. Firstly, Excel was used to preprocess students' data, and then SPSS 24.0 was used for statistical analysis. The demographic data of students were obtained directly from their status files, which would not be repeated here. Collected survey data were processed and analyzed by SPSS 24.0 to explore the key factors affecting the students' learning adaptability, and targeted educational guiding countermeasures were put forward according to the characteristics of students' adaptability at this stage.

\subsection{Investigation Process and Monitoring}

\subsubsection{Students' Self-Assessment}

In the first year of junior high school freshmen formal class about a month, the use of class meeting time grade unified organization to fill in the questionnaire.

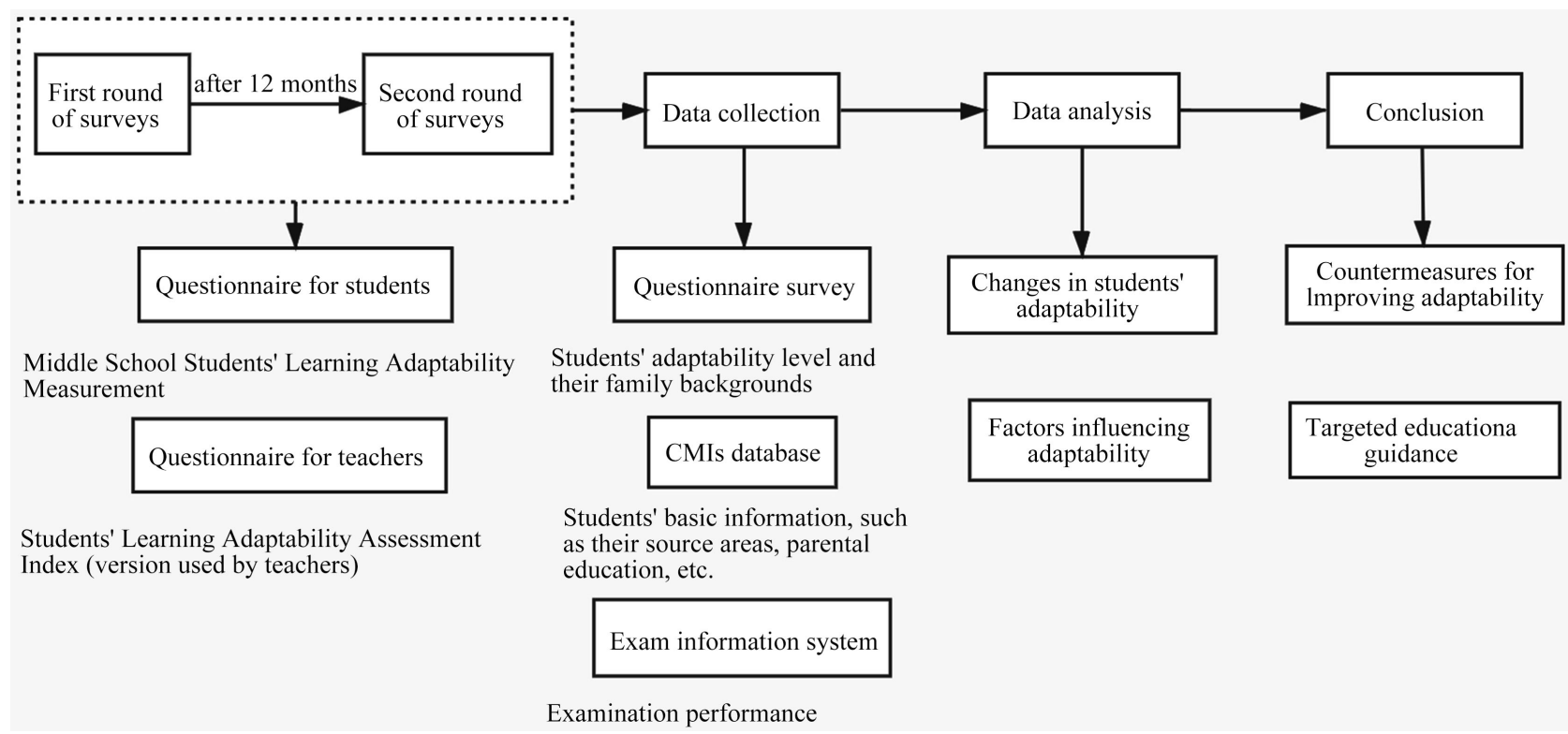

Figure 1. Research process. 
This strategy avoided the leakage of questionnaire content and students' psychological preparation in advance, which may interfere with the validity of the questionnaire. The head teacher in each class provided guidance before students filled in the questionnaire and monitored the students to finish the questionnaire. The whole test was generally required to be completed within half an hour. Those not completed within the required time didn't participate in the statistical analysis as valid test papers.

The overall development characteristics of the questionnaire data were analyzed by using the five-point scoring method. 1 to 10 classes were divided into groups in order of each two classes. The specific grouping situation (Group AE) is shown in Table 1 .

\subsubsection{Process of Adaptability Assessment Led by Teachers}

Based on the Students' Learning Adaptability Assessment Index (version used by teachers) compiled by the author, the teachers assessed the students who participated in the questionnaire survey. The 5-point scoring method was used to analyze the characteristics of each student' learning adaptability. There were 12 teachers participated in the questionnaire survey, 10 of them were head teachers, who had a more thorough understanding of students. The questionnaire was made in duplicate to ensure that the same student was assessed by the head teacher and a non-headteacher.

\section{Analysis on the Results of Pre-Test of Students' Learning Adaptability}

\subsection{Analysis of the Self-Assessment Scores of Learning Adaptability}

According to the general distribution ratio of national norm, the total score of learning adaptability is divided into five grades, which are excellent, middling above, middling, middling below, poor. According to the frequency distribution of the total score of self-assessment of learning adaptability, the frequency of self-assessment results was counted, as shown in Table 2.

\subsubsection{Classification of the Total Score of Self-Assessment of Learning Adaptability}

For the five groups participating in the adaptability evaluation, the distribution of the total score of self-assessment of learning adaptability is shown in Table 3.

As shown in Table 3, the total score of students in group E was higher than that of students in other groups, with a proportion of $82.3 \%$ above the middling grade, which was all higher than the average grade. Group B had the lowest rate of excellent grade of learning adaptability, which was $8.27 \%$ lower than the average grade. The proportion of students in group A with poor learning adaptability was the highest, accounting for $16.7 \%, 9.68 \%$ higher than the average grade. The results of self-assessment of learning adaptability were higher in group A and lower in group B. 
Table 1. Learning adaptability group.

\begin{tabular}{ccccccc}
\hline Group & $\mathrm{N}$ & Male & Female & $\begin{array}{c}\text { N } \\
\text { (Transient students) }\end{array}$ & Male & Female \\
\hline A & 54 & 27 & 27 & 8 & 3 & 5 \\
B & 71 & 35 & 36 & 9 & 5 & 4 \\
C & 72 & 38 & 34 & 12 & 5 & 7 \\
D & 70 & 37 & 33 & 13 & 7 & 6 \\
E & 62 & 33 & 29 & 8 & 6 & 2 \\
\hline
\end{tabular}

Table 2. Classification standard for learning adaptability grade.

\begin{tabular}{cccc}
\hline Standard score & Grade & $\begin{array}{c}\text { The overall distribution ratio of the } \\
\text { national norm (\%) }\end{array}$ & $\begin{array}{c}\text { Actual distribution } \\
\text { ratio (\%) }\end{array}$ \\
\hline More than 222 & excellent & 7 & 6.4 \\
$221-192$ & middling above & 24 & 23.4 \\
$191-158$ & middling & 38 & 38 \\
$157-127$ & middling below & 24 & 25.2 \\
Below 125 & poor & 7 & 7 \\
- & - & 100 & 100 \\
\hline
\end{tabular}

Table 3. Learning adaptability self-assessment total score classification.

\begin{tabular}{ccccccc}
\hline \multirow{2}{*}{ Group } & \multirow{2}{*}{$\mathrm{N}$} & \multicolumn{5}{c}{ The proportion of each grade } \\
\cline { 3 - 7 } & & Excellent & Middling above & Middling & Middling below & Poor \\
\hline A & 54 & 5.56 & 20.37 & 33.33 & 24.07 & 16.67 \\
B & 71 & 1.41 & 29.58 & 39.44 & 26.76 & 2.82 \\
C & 72 & 6.94 & 19.44 & 37.50 & 27.78 & 8.33 \\
D & 70 & 8.57 & 17.14 & 37.14 & 31.43 & 5.71 \\
E & 62 & 9.68 & 30.65 & 41.94 & 14.52 & 3.23 \\
\hline
\end{tabular}

\subsubsection{Analysis of Self-Assessment Scores of Learning Adaptability}

The self-assessment scores of each dimension of learning adaptability were further analyzed, as shown in Table 4.

Group E had the highest average score of learning adaptability, while group A had the lowest. The standard deviation of group E was the lowest only for learning attitude and learning habit, while the other two items and the total score of group B were the lowest. Group D had the highest standard deviation of study attitude and study habit, while group A had the highest of other items. Therefore, it can be seen that the overall grade of learning attitude and habit of students in group $\mathrm{E}$ is better than that of other groups, while the overall grade of learning ability and learning methods of students in group B is better than that of other groups. 
Table 4. Self-assessment scores of learning adaptability.

\begin{tabular}{cccccccccc}
\hline \multirow{2}{*}{ Group } & \multicolumn{2}{c}{$\begin{array}{c}\text { The proportion of } \\
\text { each grade }\end{array}$} & \multicolumn{2}{c}{ Learning ability } & \multicolumn{2}{c}{ Learning methods } & \multicolumn{2}{c}{$\begin{array}{c}\text { Self-assessment } \\
\text { scores }\end{array}$} \\
\cline { 2 - 9 } & Mean & Std. & Mean & Std. & Mean & Std. & Mean & Std. \\
\hline A & 45.61 & 8.127 & 47.39 & 12.189 & 72.15 & 18.84 & 165.15 & 36.442 \\
B & 47.75 & 7.006 & 48.44 & 9.071 & 78.69 & 14.645 & 174.87 & 27.209 \\
C & 47.58 & 6.282 & 48.57 & 10.154 & 75.69 & 17.025 & 171.85 & 31.01 \\
D & 46.11 & 8.217 & 48.69 & 10.851 & 78.34 & 17.02 & 173.14 & 32.679 \\
E & 49.63 & 5.949 & 52.23 & 10.069 & 84.65 & 16.145 & 186.5 & 29.362 \\
\hline
\end{tabular}

\subsection{Gender Classification Analysis of the Total Score of Self-Assessment of Learning Adaptability}

The analysis results of gender differences in self-assessment of learning adaptability are shown in Table 5 . The proportion of female students in the two grades of "excellent" and "middling above" is $34.71 \%, 10.18 \%$ higher than that of male students, indicating that the overall grade of learning adaptability of female students is better than that of male students in middle school.

The difference Tests of self-assessment scores of learning adaptability of male and female freshmen in junior high school are shown in Table 6. The test probability $P<0.05$ indicates that there are significant differences in learning adaptability of male and female freshmen in learning attitude and learning habits, learning ability and learning methods. Female scores are higher than male in each dimension of learning adaptability, so it is further verified that the overall grade of learning adaptability of female is higher than that of male.

Female students score better than male students in learning adaptability, especially in learning attitude and learning habits. This result is consistent with the domestic research of Bai Jinrong and Wang Huiping et al. This may be due to the fact that girls mature earlier than boys in primary and secondary school. In theory, female usually develop one to two years earlier than male, and their brains mature relatively early. On the other hand, social norms related to gender also make female better in work conscientiousness, emotional stability, responsibility-taking and self-consciousness in learning than male in primary and secondary school. These psychological characteristics may make girls more able to adapt to the requirements of study.

\subsection{Significance Analysis of Self-Assessment Scores of Students from Different Sources}

As shown in Table 7, self-assessment scores of learning adaptability of rural students are slightly lower than those of urban students in terms of learning attitude and learning habits, while the mean and standard deviation of other items are higher than those of urban students. T-test results show that there is no significant difference between urban and rural students' learning adaptability. 
Table 5. Total score analysis for self-assessment of learning adaptability-gender classification.

\begin{tabular}{ccccccc}
\hline \multirow{2}{*}{ Gender } & $\mathrm{N}$ & \multicolumn{5}{c}{ The proportion of each grade } \\
\cline { 3 - 7 } & & Excellent & Middling above & Middling & Middling below & Poor \\
\hline Male & 159 & 5.03 & 19.50 & 40.88 & 33.96 & 7.55 \\
Female & 170 & 7.65 & 27.06 & 35.29 & 17.06 & 6.47 \\
Difference value & - & -2.62 & -7.56 & 5.59 & 16.90 & 1.08 \\
\hline
\end{tabular}

Table 6. Difference Tests of learning adaptability self-assessment scores about gender.

\begin{tabular}{cccccc}
\hline- & - & $\begin{array}{c}\text { Learning attitudes } \\
\text { and habits }\end{array}$ & $\begin{array}{c}\text { Learning } \\
\text { ability }\end{array}$ & $\begin{array}{c}\text { Learning } \\
\text { methods }\end{array}$ & $\begin{array}{c}\text { Self-assessment } \\
\text { scores }\end{array}$ \\
\hline Male & Mean & 45.82 & 47.86 & 75.79 & 169.47 \\
Female & Mean & 49.03 & 50.35 & 80.38 & 179.75 \\
$\begin{array}{c}\text { Significance of } \\
\text { difference }\end{array}$ & $P$ & 0.000 & 0.016 & 0.013 & 0.002 \\
\hline
\end{tabular}

Table 7. Comparison of self-assessment the urban and rural students learning adaptability.

\begin{tabular}{|c|c|c|c|c|c|c|c|}
\hline \multirow[b]{2}{*}{ - } & \multicolumn{3}{|c|}{ Urban } & \multicolumn{3}{|c|}{ Rural area } & \multirow[b]{2}{*}{ Sig } \\
\hline & $\mathrm{N}$ & Mean & $\begin{array}{l}\text { Standard } \\
\text { Deviation }\end{array}$ & $\mathrm{N}$ & Mean & $\begin{array}{l}\text { Standard } \\
\text { Deviation }\end{array}$ & \\
\hline Learning attitudes and habits & 278 & 47.47 & 7.178 & 51 & 46.82 & 7.578 & $>0.05$ \\
\hline Learning & 278 & 48.90 & 10.597 & 51 & 49.94 & 9.937 & $>0.05$ \\
\hline Ability & 278 & 77.49 & 17.202 & 51 & 80.86 & 16.028 & $>0.05$ \\
\hline Learning Methods & 278 & 173.85 & 31.873 & 51 & 177.63 & 31.315 & $>0.05$ \\
\hline
\end{tabular}

However, further analysis shows that the grade of rural students above the middling grade is $2.76 \%$ lower than that of urban students, while the middling below grade is $2.77 \%$ higher than that of urban students.

The total score of rural students' learning adaptability self-assessment is mostly at the middle or middling below grade, but it cannot be ruled out that this is due to the low data validity caused by the small sample size. The chisquare test is made for the total score of learning adaptability of rural students and urban students, and the test probability $\mathrm{P}$ is greater than 0.05 . The conclusion proves once again that there is no significant difference between rural students and urban students in the overall grade of learning adaptability. Combined with Chinese policy and the actual situation analysis of the reasons were carried out. Chinese urban and rural economic and cultural grades are greatly different, the urban school education, teacher quality, family environment and so on are obviously better than the countryside. But in recent years, because the country attaches great importance to the countryside, it has accelerated the construction of the economy and culture in the countryside. Parents of rural students are also 
paying more and more attention to school education and trying their best to provide a good learning and living environment for their children, which makes the gap between urban and rural students gradually reduce.

\subsection{Correlation Analysis between Family Background and Self-Assessment Results of Students' Learning Adaptability}

This study investigated the family background of 329 participants, including the academic qualification and working status of their parents, in order to explore the relationship between family background and students' learning adaptability, and to provide more targeted guidance for students from the family level.

\subsubsection{Correlation Analysis of Parents' Working Status and Students' Learning Adaptability Self-Assessment Results}

The correlation analysis was conducted between parents' working status and students' self-assessment of learning adaptability, and the results were shown in Table 8. The research showed that fathers' working status was not correlated with students' self-assessment of learning adaptability $(P=0.122>0.05)$, while mothers' working status was significantly correlated with self-assessment of learning adaptability $(P=0.028<0.05)$.

\subsubsection{Correlation Analysis between Parents' Academic Qualification and Students' Self-Assessment of Learning Adaptability}

Parents' academic qualification was divided into one to six grades, which were junior high school below, junior high school, technical secondary school or technical school, senior high school, junior college, and bachelor's degree or above. The correlation analysis was made between the educational level of students' parents and the self-assessment level of students' learning adaptability, and the results were shown in Table 9.

It is shown that students learning adaptability self-assessment grade is significantly correlated to the Parents' academic qualification $(P<0.01)$, and the correlation coefficient with their father's academic qualification is greater than that of their mother's education, indicating that the father's academic qualification has a greater impact on students' learning adaptability than the mother's academic qualification. Parents' academic qualification is a complex latent variable, and it is difficult to establish a specific quantitative relationship between parents' academic qualification and learning adaptability due to the lack of authoritative indicators at present. This study is only for reference, and cannot change the status quo of parents' academic qualification to guide students' learning adaptability. Parents' academic qualification is still an unchangeable factor.

\section{Analysis on the Results of Post-Test Survey of Students' Learning Adaptability}

After one year of learning, the study selected group A and group E as the control group for post-test. 
Table 8. Correlation analysis between parents' working status and students' learning adaptability self-assessment.

\begin{tabular}{cccc}
\hline & - & Father working status & Mother working status \\
\hline $\begin{array}{c}\text { Self-assessment } \\
\text { grade }\end{array}$ & Correlation coefficient & 0.080 & $0.348^{\star}$ \\
& Sig & 0.122 & 0.028 \\
\hline
\end{tabular}

Table 9. Correlation analysis between parents' academic qualification and students' self-assessment of learning adaptability.

\begin{tabular}{cccc}
\hline & & Father academic qualification & Mother academic qualification \\
\hline Self-assessmen & Correlation coefficient & -0.182 & -0.167 \\
t grade & Sig & 0.001 & 0.002 \\
\hline
\end{tabular}

\subsection{Analysis of the Self-Assessment Results of Post-Test of Learning Adaptability}

\subsubsection{Classification and Comparative Analysis of the Total Score of Post-Test Self-Assessment}

The self-assessment results of the post-test of learning adaptability of the two groups were beyond our expectation. There was no significant change in the number of excellent and poor students, but there were significant changes in the number of "middling", middling above and middling below. That is to say, the changes in the self-assessment results are concentrated on the middling-level students, as shown in Table 10.

Compared with group A, group E showed a decline in the overall level of self-assessment after the post-test of learning adaptability. The overall level of students in group $\mathrm{E}$ in the post-test of learning adaptability did not improve as expected. The number of middling above and middling students had decreased to varying degrees, while the number of middling below students was increasing. As shown in Table 12, the overall level of post-test self-assessment in group A and group $\mathrm{E}$ showed great changes. The number of people in the middling above and middling levels decreased by $8.88 \%$ and $3.02 \%$ respectively, while the number of people in the middling below levels increased by $8.39 \%$.

\subsubsection{Analysis of the Difference between Pre - and Post-Test of Learning Adaptability Dimensions}

The post-test of learning adaptability of group A and group E showed a trend of "going down", especially Group E. As far as the usual learning situation is concerned, group E has a great advantage over other groups. However, the results of the post-test of learning adaptability are unexpected, with the overall level of learning adaptability is significantly lower than that of group A. However, the teachers reported that the academic performance of group E was steadily improving, and the students' learning enthusiasm was also very high which wasn't affected by the decline in the overall level of learning adaptability. Therefore, the $\mathrm{Z}$ test was performed on the pre-test and post-test of the two shifts A and E, as shown in Table 11. 
Table 10. Comparison of pre- and post-test of learning adaptability for group A and group E.

\begin{tabular}{cccccc}
\hline & \multicolumn{5}{c}{ The proportion of each grade } \\
\cline { 2 - 6 } & Excellent & Middling above & Middling & Middling below & Poor \\
\hline Group A pre-test & 5.56 & 20.37 & 33.33 & 24.07 & 16.67 \\
Group A post-test & 6.25 & 12.50 & 33.33 & 27.08 & 20.83 \\
Group E pre-test & 9.68 & 30.65 & 41.94 & 14.52 & 3.23 \\
Group E post-test & 12.07 & 20.69 & 36.21 & 27.59 & 3.45 \\
Group A\&E pre-test & 7.76 & 25.86 & 37.93 & 18.97 & 9.48 \\
Group A\&E post-test & 9.43 & 16.98 & 34.91 & 27.36 & 11.32 \\
\hline
\end{tabular}

Table 11. Difference significant analysis between the pre-test and post-test of group A and $\mathrm{E}$.

\begin{tabular}{cccccc}
\hline- & & $\begin{array}{c}\text { Learning attitudes } \\
\text { and habits }\end{array}$ & $\begin{array}{c}\text { Learning } \\
\text { ability }\end{array}$ & $\begin{array}{c}\text { Learning } \\
\text { methods }\end{array}$ & $\begin{array}{c}\text { Self-assessment } \\
\text { scores }\end{array}$ \\
\hline \multirow{2}{*}{ Pre-test } & $\mathrm{Z}$ & 5.56 & 20.37 & 33.33 & 24.07 \\
& Sig & 6.25 & 12.50 & 33.33 & 27.08 \\
& $\mathrm{Z}$ & 9.68 & 30.65 & 41.94 & 14.52 \\
Post-test & Sig & 12.07 & 20.69 & 36.21 & 27.59 \\
\hline
\end{tabular}

There were significant differences in learning adaptability between group A and group $\mathrm{E}$ in learning attitude and learning habit, learning ability, learning methods, and self-assessment scores. On the surface, the self-assessment results of the post-test of learning adaptability of group E decreased more obviously than that of group A. However, according to the average of the self-assessment scores of the post-test of learning adaptability, it can be seen that group E still has significant advantages compared with group A.

\subsection{Analysis on the Reasons Leading to the Change of Students' Self-Assessment of Learning Adaptability}

\subsubsection{The Conclusion of Self-Assessment Analysis on Learning Adaptability of Post-Test}

After one year of study, the overall level of students' self-assessment in the post-test of learning adaptability has not been expected to improve, on the contrary, it has decreased to different degrees. Therefore, the study conducted the correlation analysis of the students' self-assessment in post-test of learning adaptability, monthly examination results and grade rankings.

As shown in Table 12, there is a significant correlation between the self-assessment results of the students' learning adaptability and monthly test scores and grade rankings. Obviously, when students evaluate their own learning situation, they make judgments based on their own grades and rankings in the grade.

Therefore, the general decline of self-assessment results of students' learning 
Table 12. Correlation analysis of the students' self-assessment in post-test of learning adaptability, monthly examination results and grade rankings.

\begin{tabular}{|c|c|c|c|c|c|c|c|c|}
\hline & & \multirow{2}{*}{$\begin{array}{l}\text { Learning attitudes } \\
\text { and habits }\end{array}$} & \multirow{2}{*}{$\begin{array}{l}\text { Learning } \\
\text { ability }\end{array}$} & \multirow{2}{*}{$\begin{array}{l}\text { Learning } \\
\text { methods }\end{array}$} & \multirow{2}{*}{$\begin{array}{l}\text { Self-assessment } \\
\text { scores }\end{array}$} & \multirow{2}{*}{$\begin{array}{l}\text { Monthly exam } \\
\text { results }\end{array}$} & \multicolumn{2}{|l|}{ Grade rank } \\
\hline & & & & & & & semester & Last semester \\
\hline \multirow{2}{*}{$\begin{array}{l}\text { Monthly exam } \\
\text { results }\end{array}$} & Pearson & 0.306 & 0.513 & 0.443 & 0.467 & 1 & - & - \\
\hline & Sig & 0.001 & 0.000 & 0.000 & 0.000 & - & - & - \\
\hline \multirow{2}{*}{$\begin{array}{l}\text { Grade ranking of } \\
\text { the semester }\end{array}$} & Pearson & -0.329 & -.579 & -0.487 & -0.516 & -0.969 & 1 & - \\
\hline & Sig & 0.001 & 0.000 & 0.000 & 0.000 & 0.000 & - & - \\
\hline \multirow{2}{*}{$\begin{array}{l}\text { Grade ranking of } \\
\text { last semester }\end{array}$} & Pearson & -0.268 & -0.558 & -0.436 & -0.468 & -0.913 & 0.935 & 1 \\
\hline & Sig & 0.006 & 0.000 & 0.000 & 0.000 & 0.000 & 0.000 & - \\
\hline
\end{tabular}

adaptability may be caused by the following reasons:

1) The increase of schoolwork pressure in junior high school leads to the decrease of students' self-confidence and self-assessment results

The "happy learning" approach and evaluation in primary school make many students "feel good about themselves". The number of learning courses in junior high school has increased, the amount of learning has doubled, and the subject content tends to be specialized and abstract. All these factors make the students who feel good about themselves feel stressed and appear "unadaptable". Furthermore, after a year, students become more mature in their psychology, have more objective evaluation and higher demands on themselves. Therefore, there is a declining trend in themselves assessment.

2) "Excellent" and "poor" students have formed a relatively stable learning adaptability

The reason why the "excellent" students in the self-evaluation of students' learning adaptability do not show significant changes in the pre-test and posttest is that these students have formed good learning adaptability in primary school. With the increase of grades, students gradually formed a set of learning methods suitable for them and adapted to the learning at the junior high school stage. Students who have developed learning adaptability have correct learning attitudes, good learning habits, and outstanding learning capabilities. Therefore, the overall level of learning adaptability of these students has not changed significantly in the pre-test and post-test.

Students with poor self-assessment of learning adaptability have no significant changes in the pre-test and post-test, which is because these students always have bad learning attitude and learning habits, and pay less attention to learning in consciousness. However, in junior middle school, students' learning attitude and learning method are crucial to their learning adaptability. Therefore, students with improper attitude will obviously have a poor and relatively stable learning adaptability.

3) The "middling" students' results of self-evaluation of learning adaptability are in a state of decline

The self-assessment results of the post-test of learning adaptability of the stu- 
dents of group A and E show that the number of the students of "middling above", "middling" and "middling below" has changed greatly, that is to say, the change is concentrated on the students of "middling" level. In addition, the results of post-test self-assessment of learning adaptability of students at "middling" level are lower than those of pre-test.

\subsubsection{Analysis of the Causes of Changes in Self-Assessment of Learning Adaptability Combined with Teacher Evaluation}

This study analyzed 71 students whose self-assessment scores on the post-test of learning adaptability decreased, including 33 students from group A and 38 students from group E. In order to further verify the objectivity of students' selfassessment, this study reintroduced teacher evaluation, which included students' learning attitude, learning enthusiasm, academic performance, classroom performance, homework completion and other aspects. According to the teachers, in this year's learning process, most of the students have absolute progress, and regressive students' learning attitude is not correct, resulting in their "weariness" and "not to learn". Among the 71 students whose self-assessment score of learning adaptability decreased, 50 students were in a state of learning progress, accounting for $70.42 \%$, while only $19.72 \%$ of students showed regressive phenomenon, and 7 students kept steady, accounting for $9.86 \%$. From this, it can be seen that the teacher evaluation results further prove that the overall student's self-assessment results of learning adaptability in post-test are reduced, but it is relatively lower. It is the result of students more strictly demanding themselves, more objectively evaluating themselves, and being influenced by the outside world.

In order to further verify the decrease in the grade of post-test caused by the low self-confidence of students, one student was randomly selected from two groups A and B respectively, and the ranking of each test score was statistically analyzed, as shown in Figure 2. At the same time, the scores of the pre- and post-tests are counted, as shown in Table 13.

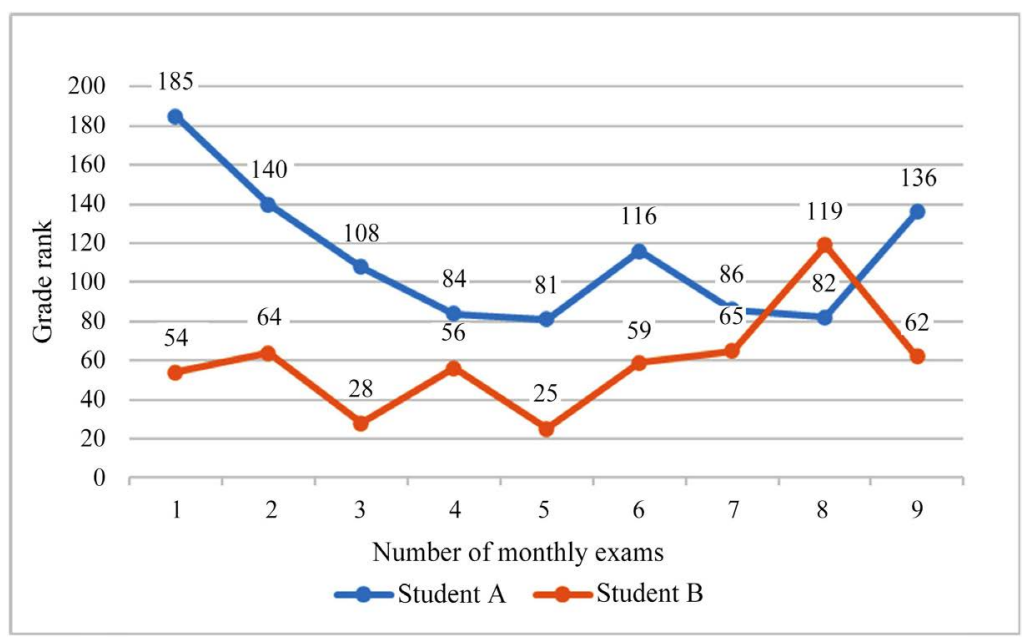

Figure 2. Student A, Student B monthly exam grade ranking. 
Table 13. Student A, B's learning adaptability pre and post test scores in various dimensions.

\begin{tabular}{cccccc}
\hline & & $\begin{array}{c}\text { Learning attitudes } \\
\text { and habits }\end{array}$ & $\begin{array}{c}\text { Learning } \\
\text { ability }\end{array}$ & $\begin{array}{c}\text { Learning } \\
\text { methods }\end{array}$ & $\begin{array}{c}\text { Self-assessment } \\
\text { scores }\end{array}$ \\
\hline \multirow{3}{*}{ Student A } & Pre-test & 53 & 51 & 89 & 193 \\
& Post-test & 44 & 42 & 73 & 159 \\
\multirow{3}{*}{ Student B } & Pre-test & 54 & 52 & 80 & 186 \\
& Post-test & 53 & 55 & 93 & 201 \\
\hline
\end{tabular}

It is found that the results of student A's self-assessment of learning adaptability change with her exam scores and ranking, especially after her ranking in the two exams has dropped significantly, which has shaken her self-confidence and self-evaluation in learning. Student A's academic performance is in a steady upward trend, although the midway monthly exam ranking has dropped sharply, but this "setback" also enables him to objectively understand his shortcomings. Student B has no significant change in learning attitude, learning habits and learning ability, so he may have found a suitable learning method for himself. His ranking fluctuated around 55, in a relatively stable state. However, the score of the eighth monthly examination dropped sharply and then improved steadily, and the self-assessment score also increased relatively, which also showed that the self-assessment level of student B's learning adaptability was affected by the score. The steadily improved score affirmed his learning method to a certain extent, and made him regain confidence and study harder.

The above analysis can also show from the side that students with intermediate grades have great flexibility in learning adaptability and are most in need of targeted guidance from teachers. Teachers should increase their observation on them, communicate with them more, help them improve their learning methods, increase their confidence in learning, and make them interested in learning, so as to generally improve their learning adaptability.

\subsubsection{Analysis on the Difference of Self-Assessment Results of Learning Adaptability between the Two Classes}

1) High-quality class students' self-confidence may be affected by heavy class pressure, leading to lower self-assessment

38 students from group E and 33 students from group A showed a trend of decline in their self-assessment scores. However, according to the data of teacher interview survey, actually only 5 students from group $\mathrm{E}$ showed a downtrend in their learning, accounting for $13.16 \%$, while 9 students from group A accounted for $27.27 \%$. This shows that the students in group E are more "strict with themselves" than the students in group A. In order to avoid the subjective judgment of teachers, this study also combined with the investigation of "Students' Learning Situation" conducted by A network school in Beijing on our students. The analysis shows that students generally feel the pressure of learning increases significantly when they enter the new learning stage in the new semester, and the 
pressure of students in group E is obviously stronger than that of students in group A. The overall level of group E students is higher than other groups, and the phenomenon of students consciously learning is more common. All these can explain that in a class with a good learning atmosphere, students have higher self-requirements, which can also explain why the self-assessment score of learning adaptability of students in group E decreases while their overall learning steadily increases.

2) Class ranking changes lead to lower self-evaluation

As shown in Table 12, the self-assessment results of students' learning adaptability in post-test are significantly correlated with the grade ranking of the examination scores. That is to say, students conduct self-evaluation according to the grade ranking of the examination scores. Further, the correlation analysis between the results of learning adaptability of 71 students with lower self-assessment scores in the post-test and their class ranking was conducted. The analysis showed that learning attitude and learning habits, learning methods, learning ability, and total self-assessment scores were significantly correlated with class ranking $(P<0.05)$. It can be seen that in addition to the examination results and grade rank, students' self-evaluation will also be judged according to their class rank.

Comparing the class ranking and grade ranking of the two classes in this month's test, it is found that the ranking of the group A is higher than that of the group E, especially among the top 200 students in the grade, that is, above "medium" students. For example, if the grade rank is $151-200$, there are 4 students in group A, whose group rank ranges from 19 to 22, while there are 3 students in group E, whose class rank ranges from 27 to 28 . As a result, students of the same or similar learning level in high-quality class are placed lower than those in ordinary class. Obviously, students in high-quality classes are bound to bear greater pressure than those in ordinary classes. The pressure may lead to students' lack of confidence, or make them strict with themselves, which affects and even leads to lower self-assessment in the post-test. This can also explain why in the self-evaluation results of the post-test, the number of students at the "middling above" and "middling" levels in group E decreased more than group A.

\section{Summary}

\subsection{Factors Influencing the Learning Adaptability of Freshmen in Junior High School}

It can be seen from the investigation and analysis of the learning adaptability of freshmen in the first grade of junior high school that the girls are significantly better than the boys in learning attitude and learning habits and total score of self-assessment. In terms of the influence of students' family background on their learning adaptability, fathers' working status has no significant correlation with students' learning adaptability, while mothers' working status has. Students' learning adaptability is also significantly related to the parents' academic quali- 
fication. Combined with teacher evaluation, it's also found that students' learning adaptability level is affected by students' class rank and grade rank. Excessive demands on themselves or lack of self-confidence will also lead to the decrease of self-assessment scores of learning adaptability.

\subsection{How to Improve Students' Learning Adaptability in Practical Teaching}

1) Measure the level of learning adaptability from many angles and at many levels in the study of learning adaptability

The self-assessment results of the post-test of this study were unexpected and far from the ideal state. Particularly, the self-assessment results of "middling" students in high-quality class showed a declining state. However, data such as teacher evaluation results and monthly examination results prove that the learning ability of the "middling" students in the declining state has been improved to a certain extent compared with that in the pre-testing period, which proves the deviation of the "middling" students in the high-quality class from the side in self-evaluation. Therefore, this study believes that the subjective survey should objectively measure the level of students' adaptability through multi-angle and multi-level data.

2) Pay attention to the group of students at the "middling" level in school education

The results of this study also sound the alarm to teachers and schools. In fact, when the phenomenon of "catching both ends" is common, it is the "middling" students who are often neglected that need the most targeted guidance from teachers. These students need more attention than the "excellent students" and "poor students". They need teachers to help them establish confidence, help them find their own learning methods, and find their own strengths and weaknesses for targeted learning, to enhance their confidence and improve the learning interest. Only in this way can we improve the student's overall quality.

3) Pay attention to the mental health of low-ranking students in high-quality classes

The research shows that there is a significant correlation between the post-test self-assessment results and the grade ranking and class ranking. For students with the same or similar learning level, their class rank in the high-quality class is lower than that in the ordinary class. Class rank makes the students in the high-quality class bear more pressure than those in the ordinary class, resulting in the lower post-test self-evaluation results of the high-quality class than that in the ordinary class. Therefore, in the daily teaching process, we should pay attention to the psychological health of the students who fall behind in the high-quality class, help them establish self-confidence and promote their healthy growth.

\section{Acknowledgements}

We are grateful to Beijing Normal University for embracing this research. 


\section{Conflicts of Interest}

The authors declare no conflicts of interest regarding the publication of this paper.

\section{References}

Bai, J. R., Liu, G. W., \& Guo, X. M. (1997). Research on Middle School Students' Learning Adaptability. Psychological dynamics, 2, 61-64+39.

Bian, Y. L., \& Tan, M. (2017). Investigation on the Current Situation of Learning Adaptability of Children of Floating Population-The Case Study of Chang Zhou Public Junior High School Students. Education Research Monthly, 5, 55-66.

Chartrand, J. (1990). A Causal Analysis to Predict the Personal and Academic Adjustment of Nontraditional students. Journal of Counseling Psychology, 37, 65-73. https://doi.apa.org/doi/10.1037/0022-0167.37.1.65

Chemers, M., Hu, L., \& Garcia, B. (2001). Academic Self-Efficacy and First Year College Student Performance and Adjustment. Journal of Educational Psychology, 93, 55-64. https://doi.apa.org/doi/10.1037/0022-0663.93.1.55

Dai, Y. H. (1997). Research on Learning Adaptability of Primary School Students. Education Guide, 1, 15-17.

Feng, T. Y., Su, T., Hu, X. W., \& Li, H. (2006). Development of College Students' Learning Adaptation Scale. Psychological Journal, 5, 762-769.

Ge, M. G., \& Yu, Y. B. (2005). College Students' Learning Adaptability and Influencing Factors. Journal of Anhui Normal University (Humanities and Social Sciences Edition), 5, 602-606.

Han, H. W. (2006). Study on the Learning Adaptability of Students in Primary and Secondary Schools in Dalian. Liaoning Normal University.

Li, K. X., \& Shi, J. P. (1998). A Study on the Development of Learning Adaptability of Rural Middle School Students. Chinese Journal of Applied Psychology, 1, 49-54.

Li, Z. L., \& Zhang, Q. L. (2004) Study on Learning Adaptation Process of Freshmen. Study on Psychology and Behavior, 1, 356-359+367.

Liao, X. R. (2014). Investigation of Senior High School Students' Adaptation to English Learning Under the Background of New Curriculum. Education Research Monthly, 7, 88-92.

Liu, X. L., Fang, Y. Y., \& Jin, Y. (2019). Research on Learning Adaptation of Primary and Middle School Students: Taking H District of Shanghai as an Example. Journal of Schooling Studies, 16, 56-63.

Liu, Y., Liu, H. Y., \& You, X. F. (2015). The Moderating Effect of Learning Adaptability on Academic Performance of Junior High School Students: Based on Multi-Level Analysis. Basic education, 12, 93-104.

Nie, Y. G., Zheng, X., \& Zhang, W. (2004). Research on Learning Adaptability of Middle School Students. Psychological Development and Education, 1, 23-28.

Santalucia, R.C., Gesten, E., Rendina-Gobioff, G., Esptein, M., Kaufmann, D., Salcedo, O. et al. (2000). Children's School Adjustment. A Developmental Transactional Systems Perspective. Journal of Applied Developmental Psychology, 21, 429-446. https://doi.org/10.1016/S0193-3973(00)00048-4

Song, G. W. (1999). Studies on the Relationship between Learning Adaptability, Personality Traits and Mental Health of Middle School Students. Psychological Exploration, 1, 44-47. 
Tian, L. (2004) Review of Studies on Learning Adaptability of Primary and Middle School Students in China. Psychological science, 27, 502-504.

Tian, L., \& Zhang, D. J. (2004). A Survey of 409 Students' Learning Adaptability in a Primary School in Chongqing. Chinese School Health, 1, 23-24.

Wei, Y. H. (2004). Research on the Influence of Parenting Style on Self-Esteem Development of Children. Development and Educational Psychology, 3, 7-11.

Zeng, J. (2007). Research on the Development Characteristics of Middle School Students' Learning Adaptability. Modern Primary and Secondary Education, No. 8, 43-47.

Zhang, C. F., \& Zhang, J. B. (2000). Investigation and Analysis on Middle School Students' Learning Adaptability. Shandong Educational Research, No. z1, 60-61.

Zhang, L. H., \& Zhang, L. (2006). A Preliminary Study on the Learning Adaptability of Primary and Secondary School Students in the Transitional Stage. Journal of Liaoning Normal University (Social Science Edition), 2, 51-54.

Zhao K. Y., Huang, X. J., Yang, X., \& Zhao, J. M. (2018). The Effect of Left-at-Home Rural Children's Family Environment on Their Learning Socialization: The Mediating Effect of Learning Adaptability. Chinese Journal of Special Education, 3, 65-71. 